\title{
THE THIAMIN CONTENT OF HUMAN BLOOD AND URINE AS DETERMINED BY THE FERMENTATION METHOD ${ }^{1}$
}

\author{
By ROBERT GOODHART WITH THE TECHNICAL ASSISTANCE OF THEODORA NITZBERG
}

(From the Department of Medicine, New York University College of Medicine; and the Medical Service of the Psychiatric Division, Bellevue Hospital, New York)

(Received for publication June 9, 1941)

In 1937, Schultz, Atkin and Frey (1) published the first of a series of articles on the stimulating effect of thiamin upon the rate of alcoholic fermentation by yeast. Subsequently they described the experimental conditions under which this activity could be taken advantage of to measure the thiamin content of biological materials. The stimulating effect of thiamin was found to be complicated by an additional stimulation of the pyrimidine half of the molecule (2-methyl-5hydroxymethyl-6-aminopyrimidine). They stated that similar or related compounds were inactive, although they did not mention the substances tested (2).

As 2-methyl-5-hydroxymethyl-6-aminopyrimidine has not been shown to occur in nature, except as a component of, or a degradation product of, thiamin, its presence probably does not seriously invalidate the method as a means for estimating blood and urine thiamin values in the human subject.

Schultz, Atkin and Frey $(3,4)$ recently described a method for the determination of what they termed the "true" thiamin content of urine. In this method they took advantage of the fact that the oxidation of thiamin to thiochrome renders it biologically inactive. They measured the total fermentative power of a sample of urine and subtracted from this the fermentative power of an oxidized aliquot portion. The resulting value represented free pyrimidine in the urine. We attempted this procedure but have discarded it because of inaccuracies resulting largely from incomplete oxidation.

These workers also tested the effect of added adenylic acid in their system and found it to be inactive (5). Nicotinic acid was found to have

1 This work has been aided by grants from the Dazian Foundation for Medical Research and the Nutritional Research Fund of the Psychiatric Division of Bellevue Hospital. a stimulating effect in the presence of thiamin (5). This effect was of a very small order and was maximum with a concentration of $1 \mathrm{mgm}$. per cent of the acid. Nicotinamide was found to have an activity of the same order as nicotinic acid. Schuiltz, Atkin and Frey therefore modified their technique to include this concentration of nicotinic acid in their stock solution (5). However, as the concentration of nicotinic acid in blood is only about $0.36 \mathrm{mgm}$. per cent, and as the fermentation method, when applied to the estimation of thiamin in blood, requires the use of only $0.1 \mathrm{cc}$. of this substance, the amount of nicotinic acid in the blood could not be an important source of error. As the concentration of nicotinic acid in urine is of the same order, the above statement also holds true for urine.

We have used the fermentation method for the study of the blood and urine concentrations of thiamin in normal human subjects and in subjects suffering from a variety of diseases.

\section{EXPERIMENTAL}

The method used for the determination of thiamin in both blood and urine was that described by Atkin, Schultz and Frey as the "Ultramicrodetermination" method (6). We made only two modifications: The first was in the preparation of the thiamin stock solution, which was made up so that $1 \mathrm{cc}$. contained $2.5 \mathrm{mgm}$. of thiamin in 30 per cent acid alcohol. The stock solution was stored in the ice box. The amount required for each experiment was obtained by evaporating a sufficient quantity of the stock solution to dryness, and then on the day of the experiment, making up to the correct dilution with distilled water. Second, the yeast suspension was freshly prepared for each experiment.

The bloods used for the estimation of their thiamin content were obtained from fasting subjects. Two mgm. of potassium oxalate per cc. of blood were used to prevent clotting. We have not been able to demonstrate any inhibitory or adjuvant effect of this concentration of potassium oxalate upon the fermentation of glucose by bakers' yeast, either in the presence or the absence of crystalline thiamin.

Urinary estimations were done on 24-hour urine sam- 
ples, collected in bottles containing $10 \mathrm{cc}$. of $5 \mathrm{~N}$ Hydrochloric acid. Urine collected this way was found to remain stable for several days, if stored in the ice box. When simultaneous blood and urine estimations were performed, the blood was drawn at the end of the 24-hour urine collection period. For the estimation of normal blood and urine values, samples were obtained from interns, research workers, and patients on the wards of the Psychiatric Division of Bellevue Hospital who presented no clinical manifestations of somatic or mental disease other than psychoneurosis.

Each experimental run included, in addition to the unknowns and the yeast blanks, a determination of the fermentative effect of at least one known amount of thiamin. All determinations were made in duplicate.

As the sensitivity of the method permitted the use of only very small amounts of blood and urine, greater accuracy was obtained by diluting fairly large quantities of the unknown to an extent that allowed the pipetting of 1 cc. of the final dilution directly into the fermentation vessel. For example, when $0.1 \mathrm{cc}$. of blood was to be used, $5 \mathrm{cc}$. of blood were diluted with $0.5 \mathrm{cc}$. of the gelatin solution and distilled water sufficient to bring the total volume up to $50 \mathrm{cc}$. One cc. of this solution was then pipetted into the fermentation vessel.

When tests for the recovery of thiamin were run, the thiamin was added to the blood or urine before the dilutions were made.

In Figure 1 are charted typical curves of response of $5 \mathrm{mgm}$. of yeast ${ }^{2}$ to thiamin. The response of yeast to thiamin varies not only with each lot of yeast, but also with each suspension made. Because of this, it is necessary to run at least one point on the curve with each experiment. All the curves fall off with increasing rapidity as the amounts of thiamin increase. It is necessary, therefore, to use amounts of the unknown which contain no more thiamin than the amount used for the portion of the curve determined with that particular experimental run. As the curve is steepest with amounts of thiamin below $0.01 \mathrm{mi}-$ crogram, greater sensitivity and accuracy are obtained when amounts of the unknown giving values less than this are used. We have found that, with normal and deficient bloods, $0.1 \mathrm{cc}$. is the optimum amount. The corresponding amount for urines was found to be $0.01 \mathrm{cc}$. When unusually large amounts of thiamin have been administered to the subject before the collection of the blood and urine, smaller amounts of these materials should be used for the determinations.

2 Supplied by Dr. Charles N. Frey, Fleischmann Laboratories, New York.

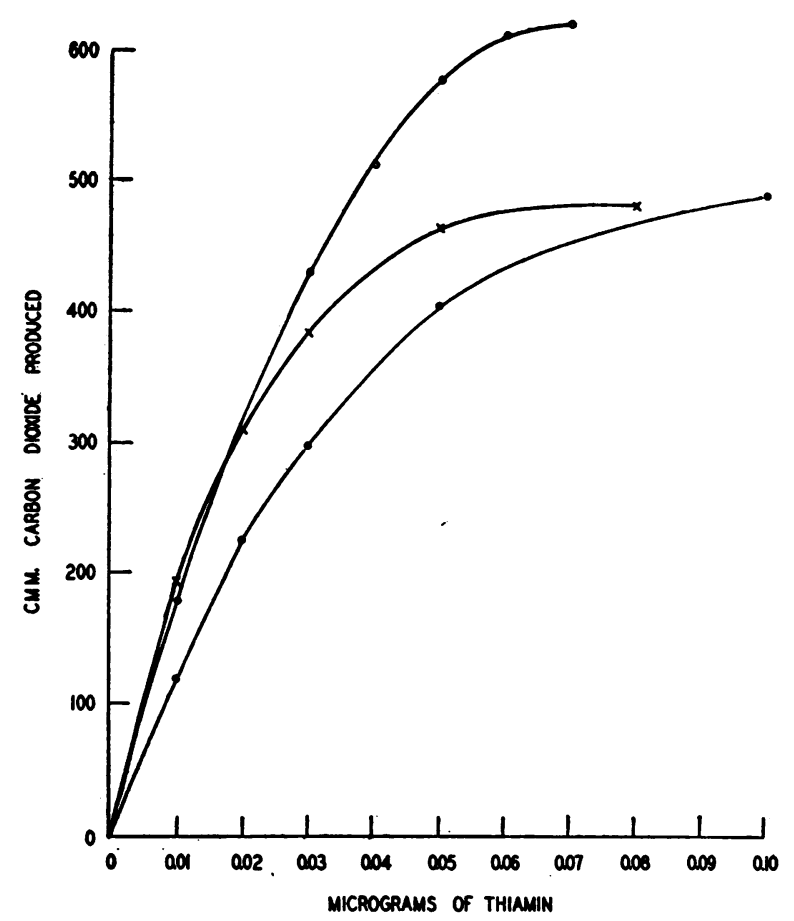

Fig. 1. The Adjuvant Effect of Thiamin upon Carbon Dioxide Produced by Glucose Fermentation with 5 mgm. Portions of Bakers' Yeast

Atkin, Schultz and Frey prepared their protein samples for analysis by heating them at $100^{\circ} \mathrm{C}$. for 30 minutes, after they had been made acid to congo red (6). We tried the effect upon the gas production of heating the bloods, without acidification, in a boiling water bath for varying time intervals (Table $I$ ). Increasing the time of heating proved to decrease the amount of gas evolved with

TABLE I

Effect of duration of heating upon apparent thiamin content of 0.1 ce. of blood

\begin{tabular}{|c|c|c|c|c|c|c|c|}
\hline $\begin{array}{c}\text { Exper- } \\
\text { iment } \\
\text { Num- } \\
\text { ber }\end{array}$ & $\begin{array}{c}\text { Min- } \\
\text { utes } \\
\text { heated }\end{array}$ & $\begin{array}{c}\text { Micro- } \\
\text { liters } \\
\mathrm{CO}_{2} \\
\text { pro- } \\
\text { duced* }\end{array}$ & $\begin{array}{c}\text { Micro- } \\
\text { grams } \\
\text { of } \\
\text { thiamin }\end{array}$ & $\begin{array}{c}\text { Exper- } \\
\text { iment } \\
\text { Num- } \\
\text { ber }\end{array}$ & 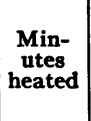 & $\begin{array}{c}\text { Micro- } \\
\text { liters } \\
\mathrm{CO}_{2} \\
\text { pro- } \\
\text { duced* }^{*}\end{array}$ & $\begin{array}{l}\text { Micro- } \\
\text { grams } \\
\text { of } \\
\text { thiamin }\end{array}$ \\
\hline 1 & $\begin{array}{r}3 \\
15\end{array}$ & $\begin{array}{r}166 \pm 2 \\
93 \pm 1\end{array}$ & $\begin{array}{l}0.0113 \\
0.0063\end{array}$ & 4 & $\begin{array}{l}3 \\
6 \\
9\end{array}$ & $\begin{array}{l}80 \pm 2 \\
70 \pm 4 \\
70 \pm 0\end{array}$ & $\begin{array}{l}0.0067 \\
0.0058 \\
0.0058\end{array}$ \\
\hline 2 & $\begin{array}{r}3 \\
9 \\
12 \\
15\end{array}$ & $\begin{array}{l}124 \pm 2 \\
115 \pm 3 \\
119 \pm 2 \\
103 \pm 2\end{array}$ & $\begin{array}{l}0.0074 \\
0.0069 \\
0.0071 \\
0.0061\end{array}$ & 5 & $\begin{array}{r}3 \\
15\end{array}$ & $\begin{array}{l}93 \pm 4 \\
88 \pm 3\end{array}$ & $\begin{array}{l}0.0052 \\
0.0049\end{array}$ \\
\hline 3 & $\begin{array}{l}3 \\
6\end{array}$ & $\begin{array}{l}159 \pm 4 \\
142 \pm 3\end{array}$ & $\begin{array}{l}0.0072 \\
0.0064\end{array}$ & 6 & $\begin{array}{r}3 \\
12 \\
15\end{array}$ & $\begin{array}{l}80 \pm 1 \\
66 \pm 2 \\
67 \pm 3\end{array}$ & $\begin{array}{l}0.0065 \\
0.0053 \\
0.0054\end{array}$ \\
\hline
\end{tabular}

* Average of duplicate determinations \pm deviations from average. 
TABLE II

Relation of duration of heating to recovery of thiamin from $0.1 \mathrm{cc}$. of blood and $0.01 \mathrm{cc}$. of urine

\begin{tabular}{c|c|c|c|c|c}
\hline \hline $\begin{array}{c}\text { Minutes } \\
\text { heated }\end{array}$ & Sample & $\begin{array}{c}\text { Micro- } \\
\text { grams } \\
\text { in sample }\end{array}$ & $\begin{array}{c}\text { Micro- } \\
\text { grams } \\
\text { added }\end{array}$ & $\begin{array}{c}\text { Micro- } \\
\text { grams } \\
\text { recovered }\end{array}$ & $\begin{array}{c}\text { Per cent } \\
\text { of } \\
\text { added } \\
\text { thiamin } \\
\text { recovered }\end{array}$ \\
\hline 3 & Blood & 0.00367 & 0.01 & 0.01567 & 120 \\
3 & Blood & 0.00367 & 0.02 & 0.02907 & 127 \\
4.5 & Blood & 0.0067 & 0.01 & 0.0169 & 102 \\
4.5 & Blood & 0.0067 & 0.02 & 0.0257 & 95 \\
6 & Blood & 0.00865 & 0.01 & 0.01735 & 87 \\
6 & Blood & 0.00865 & 0.02 & 0.02585 & 86 \\
3 & Urine & 0.00855 & 0.01 & 0.01925 & 107 \\
3 & Urine & 0.00855 & 0.02 & 0.03235 & 119 \\
4.5 & Urine & 0.0033 & 0.01 & 0.0144 & 102 \\
4.5 & Urine & 0.0033 & 0.02 & 0.0253 & 105 \\
\hline
\end{tabular}

1 cc. of blood. Studies on the recovery of thiamin, added to bloods and urines, were therefore performed after heating the samples for different time intervals (Table II). It was found that the best recoveries were obtained in the case of both blood and urine when 4.5 minutes was allowed for the period of heating.

It would seem from these experiments that there exists in blood a heat labile factor which stimulates the fermentative action of thiamin. Prolonged heating of non-acidified blood tends to destroy the biological activity of thiamin, or at least in some way to remove it from the reaction.

As a result of these experiments, we adopted the procedure of heating the bloods and urines, after diluting and pipetting into the fermentation vessels, for 4.5 minutes in a boiling water bath.

\section{RESULTS}

Eighty-six determinations of the thiamin content were made on bloods drawn from 45 presumably normal subjects. The average value found for these bloods was 5.39 micrograms per cent, with a range from 3.1 to 9.2 micrograms. The distribution of these values is shown in Figure 2.

In 1939, Goodhart and Sinclair published values for the cocarboxylase content of normal human bloods (7). They found a range from 4.5 to 12.0 micrograms per cent with a mean of 7.0. These findings were essentially confirmed by Goodhart (8) in a later work with the same method. Ex-

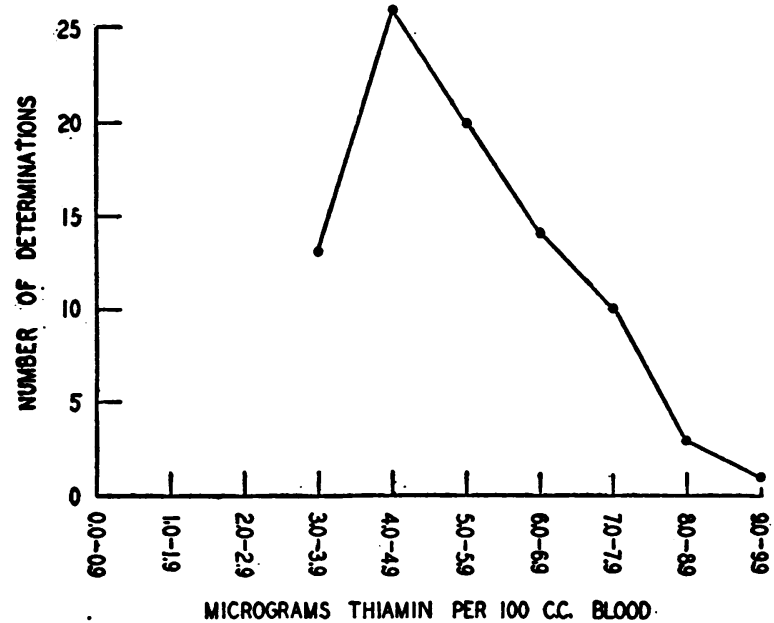

Fig. 2. Distribution of Normal Blood Thiamin Levels-86 Determinations on 45 Subjects

pressed as thiamin, this would be equivalent to a mean blood content of 4.76 with a range from 3.06 to 8.16 micrograms per cent. As the free thiamin content of human bloods is quite small, these figures agree reasonably well with those given above for the total thiamin content of normal human bloods.

The 24-hour urinary excretion of thiamin was also determined in 11 normal subjects (42 determinations). The range was found to be from 240 to 1327 micrograms, with an average of 596 micrograms for the 24-hour urinary excretion. The distribution of these values is shown in Figure 3.

Considerably higher values are obtained for the apparent thiamin content of urine when the fermentation method is used than is found by most other procedures. This is due to the large urinary content of 2-methyl-5-hydroxy-methyl-6-aminopyrimidine, a substance which also stimulates the fermentation of glucose by yeast. From the work of Schultz, Atkin and Frey (4), it would appear

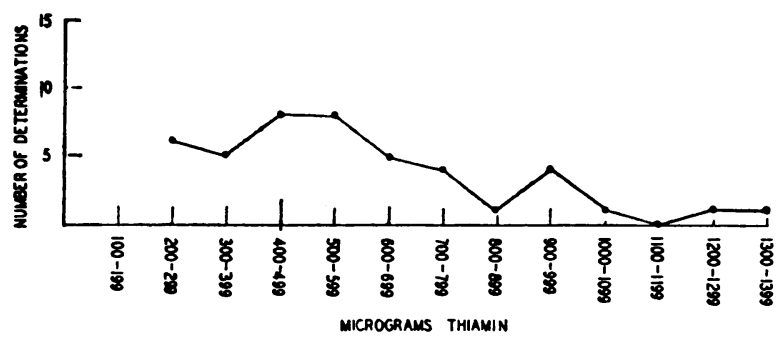

Fig. 3. Distribution of 24-Hour Urinary Excretion Values of 11 Normal Subjects-42 Determinations 
TABLE III

Relation of 24-hour urinary excretion of thiamin to fasting blood level and to dietary intake in normal subjects

\begin{tabular}{c|c|c|c|c|c}
\hline \hline Subject & $\begin{array}{c}\text { Dietary } \\
\text { intake }\end{array}$ & $\begin{array}{c}\text { Vitamin } \\
\text { calorie } \\
\text { ratio }\end{array}$ & $\begin{array}{c}\text { Blood } \\
\text { thiamin }\end{array}$ & $\begin{array}{c}\text { Urinary } \\
\text { excretion }\end{array}$ & $\begin{array}{c}\text { Intake } \\
\text { excreted }\end{array}$ \\
\cline { 2 - 5 } L & $\begin{array}{c}\text { micro- } \\
\text { grams }\end{array}$ & & $\begin{array}{c}\text { micro- } \\
\text { grams } \\
\text { per cent }\end{array}$ & $\begin{array}{c}\text { micro- } \\
\text { grams }\end{array}$ & per cent \\
& 1211 & 2.35 & 6.2 & 506 & 41.8 \\
& 1455 & 2.47 & 4.1 & 606 & 41.6 \\
& 1045 & 2.03 & 7.2 & 820 & 78.4 \\
S & 1073 & 2.04 & 5.0 & 682 & 63.6 \\
& & & & & \\
& 898 & 2.28 & & 250 & 27.8 \\
& 1328 & 2.51 & 6.8 & 384 & 28.9 \\
& 1283 & 2.56 & 4.3 & 362 & 28.3 \\
& 1222 & 2.06 & 4.3 & 795 & 65.9 \\
& 1397 & 2.83 & 5.4 & 539 & 38.6 \\
& 1409 & 2.44 & 5.0 & 502 & 35.6 \\
& 1493 & 2.79 & 4.9 & 798 & 53.4 \\
& 1063 & 2.21 & 6.2 & 929 & 86.8 \\
& 1045 & 2.01 & 5.7 & 721 & 69.0 \\
& 1455 & 2.47 & 5.9 & 1016 & 69.8 \\
\hline
\end{tabular}

that this pyrimidine may account for anywhere from 23 to 75 per cent of the " total thiamin " content of normal human urines, as estimated by the fermentation method. This means that the absolute figures obtained for urinary thiamin by the fermentation method, as used in our work, are not analagous to those obtained by other methods.

Schultz, et al. found the average daily urinary output of 5 normal adults, 32 determinations, to be $497.7 \pm 47$ micrograms (9). We found a much greater variation in the urinary excretion of thiamin, not only in different subjects but in the same individual from day to day. The explanation for this may rest, in part, in the fact that our subjects were mostly hospital patients, representing the lowest income group of the community. Their previous levels of tissue saturation with the vitamin may therefore have been both low and variable. However, the range of values found in 19 determinations on 4 interns was identical with that of the whole group. The individual interns showed differences between their highest and lowest daily urinary excretions of $410,65,113$ and 337 micrograms, respectively. As our subjects were maintained with unrestricted diets and unrestricted activity, the finding of large variations in the urinary excretion of thiamin was not unexpected.

The diets of 3 of our subjects were carefully noted during the periods of urine collection and the vitamin intake was computed. On reference to Table III it will be seen that, in spite of their very moderate intake of thiamin, they excreted a relatively large percentage in the urine, none excreting less than 27.8 per cent. In these subjects, whose dietary intake ranged from 898 to 1493 micrograms of thiamin daily, no correlation could be found between the urinary excretion, the intake, the vitamin/calorie ratio of the diet, or the fasting blood level of thiamin. It would appear that marked variations in the daily urinary excretion of thiamin may occur in normal subjects maintained with fairly constant daily intakes. This must be considered when attempting to evaluate the significance of 24-hour urinary excretions.

In Figure 4 are tabulated the results of the blood thiamin determinations on 106 patients from the wards of the Psychiatric Division of Bellevue Hospital. A solid line is drawn across the graph

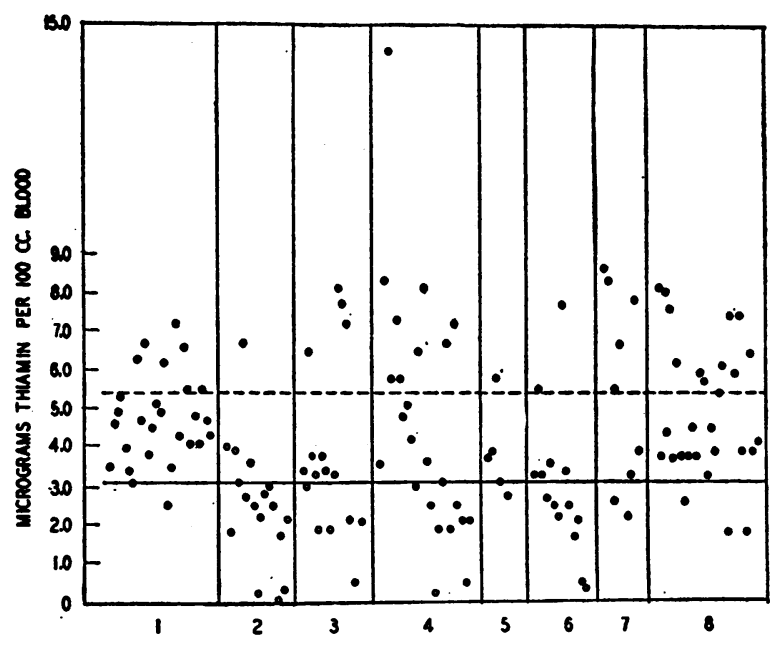

Fig. 4. Blood Thiamin Values of 106 Subjects from the Wards of the Psychiatric Division of Bellevue Hospital

- represents results on subjects without polyneuropathy. O represents results on subjects with polyneuropathy.

The column numbers (figures on horizontal scale) denote the following conditions:

(1) "Uncomplicated alcoholics."

(2) Acute "alcoholic" polyneuropathy.

(3) Chronic "alcoholic" polyneuropathy.

(4) The fatty and cirrhotic livers of the inebriate.

(5) "Alcoholic" pellagra.

(6) "Alcoholic" encephalopathies.

(7) Korsakoff psychosis.

(8) Non-alcoholic patients with a variety of medical and psychiatric disorders. 
at the lowest observed normal value. A broken line is drawn at the level of the average value found for our group of " normal" subjects.

The 27 " uncomplicated alcoholics" plotted in column 1 were admitted to the hospital with diagnoses as diverse as lobar pneumonia and acute alcoholism. All were alike in showing no clinical evidences of any vitamin deficiency. All but one had blood thiamin levels within normal limits, albeit the average of their values was considerably below that of the normal group. The one subject who had a definitely subnormal blood thiamin content was admitted to the hospital suffering from acute alcoholic intoxication and hypoglycemic shock. He was treated with glucose infusions and the blood thiamin determination was made on the following day, at which time he was asymptomatic. The possible relationship of this succession of events to his low blood thiamin content is obvious.

The results on subjects with acute "alcoholic" polyneuropathy are listed in column 2 ; those with chronic neuropathy, in column 3. Calf muscle tenderness and solar dysesthesia were taken as the necessary criteria for the diagnosis of an acute neuropathy. No attention was paid to the history of the duration of the disease as such histories, from alcohol addicts, are worthless. Twelve of the 17 subjects with acute neuropathy had blood thiamin levels definitely below the lowest observed normal value. Four of the remaining 5 subjects had blood values which were definitely low normal. In contradistinction to these results, 10 of the 16 subjects who presented the signs of chronic neuropathy alone had blood thiamin values within the normal range. As there is no reason to believe that these two conditions are not different stages of the same disease, it would seem that in the second instance we are dealing, in many cases, with the residuum of an earlier, acute process which is characteristically associated with low blood thiamin values. It is not meant to imply that thiamin deficiency is the only possible etiological agent for all the polyneuropathies which may occur in the alcohol addict. The evidence presented here neither confirms nor denies the validity of this supposition.

Low blood thiamin values were found in subjects with fatty and cirrhotic livers, "alcoholic" encephalopathic states, alcoholic pellagrins, and Korsakoff psychosis only when peripheral neuropathy was also present. This finding correlates very well with our clinical impressions acquired from therapeutic trials of thiamin hydrochloride in these different disease states. We have noted, for example, a complete lack of improvement in fatty and cirrhotic livers, when treated with large doses of thiamin hydrochloride. At the same time, we have observed that the peripheral neuropathy, when present, improved as rapidly in these subjects, when treated with thiamin, as it did in the absence of clinical evidence of liver disease. Again, the polyneuropathy of the pellagrin has been shown to respond to treatment with crystalline thiamin. Of 3 subjects with Wernicke's encephalopathy, all had low blood thiamin values and all had peripheral neuropathy. This is in accord with the findings of Jolliffe, et al. (10) and we believe constitutes confirmatory evidence that this condition is closely associated with thiamin deficiency. Bowman, $e t$ al. (11), were unable to obtain any substantial evidence, from therapeutic trials with the vitamin, that thiamin deficiency played a rôle in the production of Korsakoff's psychosis.

The findings on 28 non-alcoholic patients presenting a variety of medical and psychiatric disorders are recorded in column 8, Figure 4. This group comprised 9 subjects with general and cerebral arteriosclerosis, 5 with tuberculosis, 2 with hypertensive encephalopathy, 2 diabetics, 1 of whom had severe acute and chronic peripheral neuropathy, 4 schizophrenics, and 1 case each of psychoneurosis, manic-depressive psychosis, pernicious anemia, rheumatic arthritis, benign spinal cord tumor and lympho-epithelioma of the nasopharynx. Three definitely low blood values were found, one in a subject with general and cerebral arteriosclerosis, one in a case of miliary tuberculosis and the third in the subject with lymphoepithelioma. The distribution of the blood thiamin values in the remainder of this group was not significantly different from that of the normal control group.

The high incidence of peripheral neuritis (18 out of 22 cases) found among those subjects who had blood thiamin values below 3.1 micrograms per 100 cc. suggests to us the probability that such low blood values may be indicative of the exist- 
ence of definite thiamin deficiency states in the human subject.

\section{SUM MARY}

We elected to use the fermentation method for the studies reported in this paper because it appeared to us, at the time, that this method offered certain very definite advantages over all other available methods for the determination of thiamin in body fluids. First, the procedure of the fermentation method is simple and rapid and, although the initial cost of equipment is rather large, the subsequent expense is minimal. Second, the method promised to be much more applicable to routine estimations on hospital and clinic patients than cocarboxylase determinations since, in the former, live yeast is used, and the enzyme system is considerably more stable. Third, the fermentation method is immensely more sensitive than the " diazo method" used by Melnick and Field (12). Fourth, the thiochrome method in our hands has proved rather unsatisfactory, an experience which we know to have been shared by many other investigators; witness the large number of modifications of the thiochrome method. As a result of our work, we have been convinced of the genuineness of these advantages.

There exists in blood a heat labile factor which stimulates the fermentative action of thiamin. Prolonged heating of non-acidified blood at $100^{\circ}$ C. tends to destroy the biological activity of its thiamin. Optimal results are obtained with the fermentation method when the blood or urine is heated at $100^{\circ} \mathrm{C}$. for 4.5 minutes.

An average value of 5.39 micrograms per 100 cc., with a range from 3.1 to 9.2 , was obtained for 86 determinations on bloods drawn from 45 normal subjects.

Forty-two determinations of the 24-hour urinary excretion of thiamin, on 11 normals, gave an average of 596 micrograms, with a range from 240 to 1327 . The urinary excretion of thiamin in normal subjects was found to depend upon factors other than the total thiamin intake and the vitamin/ calorie ratio of the diet.

A very definite association was found to exist between the acute peripheral neuropathy of the alcohol addict and low blood thiamin values. The incidence of peripheral neuropathy among subjects with low blood values was so high as to make it seem likely that further work will prove the finding of a blood thiamin value below 3.0 micrograms per cent, by the fermentation method, to be definite indication of a thiamin deficiency state.

\section{BIBLIOGRAPHY}

1. Schultz, A. S., Atkin, L., and Frey, C. N., Fermentation test for vitamin $B_{1}$. J. Am. Chem. Soc., 1937, 59, 948.

2. Idem, A fermentation test for vitamin $\mathrm{B}_{1}$. Ibid., 1937, 59, 2457.

3. Idem, The specificity of the fermentation test for vitamin $B_{1}$. Ibid, 1938, 60, 3084.

4. Idem, A method for the determination of thiamine and certain of its metabolic products in urine. J. Biol. Chem., 1940, 136, 713.

5. Idem, Influence of nicotinic acid on the fermentation method for vitamin $B_{1}$ determination. J. Am. Chem. Soc., 1938, 60, 1514.

6. Atkin, L., Schultz, A. S., and Frey, C. N., Ultramicrodetermination of thiamine by the fermentation method. J. Biol. Chem., 1939, 129, 471.

7. Goodhart, R., and Sinclair, H. M., Estimation of cocarboxylase (vitamin $B_{1}$ diphosphate ester) in blood. Biochem. J., 1939, 33, 1099.

8. Goodhart, R., A revaluation of the method described by Goodhart and Sinclair for the determination of blood cocarboxylase values. J. Biol. Chem., 1940, 135, 77.

9. Schultz, A. S., Light, R. F., and Frey, C. N., Vitamin $B_{1}$ metabolism in man. Excretion of $B_{1}$ in urine and feces. Proc. Soc. Exper. Biol. and Med., 1938, 38, 404.

10. Jolliffe, N., Wortis, H., and Fein, H. P., The Wernicke syndrome. Arch. Neurol. and Psychiat. (In press.)

11. Bowman, K. M., Goodhart, R., and Jolliffe, N., Observations on rôle of vitamin $B_{1}$ in etiology and treatment of Korsakoff psychosis. J. Nerv. and Ment. Dis., 1939, 90, 569.

12. Melnick, D., and Field, H., Jr., Chemical determination, stability, and form of thiamine in urine. $\mathrm{J}$. Biol. Chem., 1939, 130, 97. 